\title{
Obituary
}

\section{Reginald George Maling (1 December 1927-3 January 2007)}

Spinal Cord (2007) 45, 466-467; doi:10.1038/sj.sc.3102050

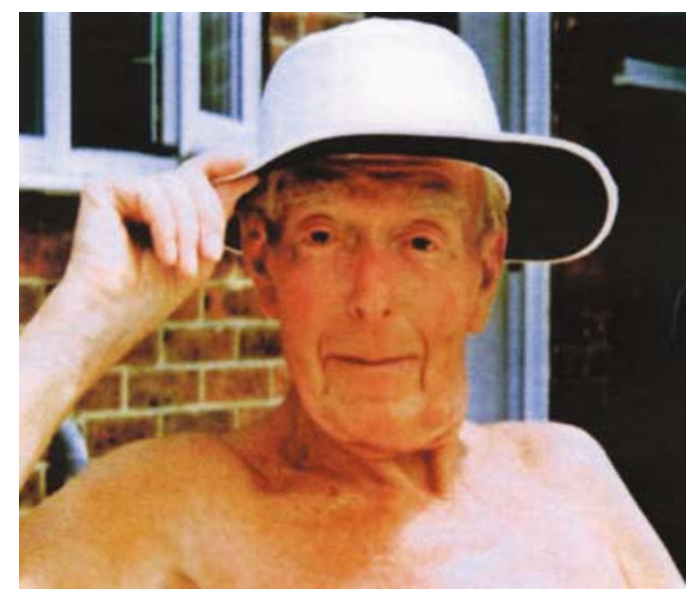

In the 1960s, the fate of a tetraplegic patient with a complete lesion was dire. Patients were told that they had 6 months to live and if they survived the initial acute injury, they were completely helpless, confined to a wheelchair and having to summon assistance for such tasks as having their teeth cleaned, washing, lighting a cigarette or turning on the television.

The situation changed dramatically when Reginald Maling, a young voluntary care worker, came to the spinal unit at Stoke Mandeville in the 1960s and was confronted with a 33-year-old tetraplegic patient, Ian Pritchard, who had been admitted 3 weeks previously from Rhodesia, after a water skiing accident. He was an outstanding athlete who sustained a fracture dislocation of the fifth cervical vertebrae, resulting in a complete C5 lesion. There was no recovery. Ian was full of determination and did have mouth function in the shape of control of a whistle. Blowing the whistle required considerable effort. Reg. realised that if patients were able to control the air in their mouth to blow on a whistle, then the same process could be used to operate micro switches, and thereby enable them to control any number of electrical appliances. In fact from a mechanical point of view, the mouth is a remarkably good pneumatic controller, capable of very precise applications of pressure. He carried out experiments that were so successful that in 1961, Action Medical Research funded this research and, together with Derek Clarkson, Reg. developed POSSUM, Patient Operator Selector Mechanism; 'Possum' in Latin means 'I am able'.
The unit was based at Stoke Mandeville Hospital, progress was rapid and within months the instrument was giving patients control over bells, lights, radios, telephones and televisions. More advanced applications were implemented to control a typewriter. The technology was internationally recognised with major scientific awards. It was realised that there was a great need for this equipment in the rehabilitation of tetraplegic patients and to allow them the greatest possible degree of independence. This was recognised by the National Health Service and in every region of the country there was a consultant advisor to see that POSSUM could be installed in the patients' homes. The concepts were very original and different systems were set up throughout the world.

Reginald George Maling was born in Aylesbury on 1 December 1927. He first showed an interest in electrical engineering at the age of 5 when he constructed an electric fence around his garden to prevent the neighbouring children from coming in and breaking his toys. He went on to Aylesbury Grammar School where he showed an innovative spirit in the 6th form in his physics practical experiments. He carried out his national service where, by all accounts, he was an eccentric soldier who did not respond in the appropriate manner to military life but the aura of gung hoe enthusiasm stuck with him. He trained as an electrical engineer and worked in Aylesbury in industry, it was at this time, while working as a volunteer in the spinal unit, that he obtained a grant from the Action for the Crippled Child, later to become Action Medical Research. He worked full time, $24 \mathrm{~h}$ a day, 7 days a week, at the spinal unit, where he was always on call for any electrical fault in the equipment and the ventilators, anticipating power failures before they occurred. He was always courteous, kind, humorous, single minded in his devotion to the patients and indefatigable in his efforts to help them. Patients still remember his kindness and courtesy to this day. He always pursued what he thought was right and, on many occasions, this led to clashes. He decided that he should exhibit at a rehabilitation conference without obtaining prior permission. He drove a trailer of equipment across Europe. This single-mindedness and unwillingness to compromise with his integrity was not welcomed in the rigid, hierarchical and dictatorial situation at the National Spinal Injury Centre; he was a free spirit. Unfortunately he had to leave and set up an independent company to 
produce this equipment in Aylesbury. This severing of active links with the patients and the circumstances left Reg. justly and extraordinarily bitter. It left the patients all the poorer and the spinal unit bereft of an innovative, courteous, devoted man of original thought.

Reg. learned to fly so that he could deliver the equipment promptly and on one occasion, while on holiday, there was a rescue attempt in the Irish Sea and he led the expedition flying his own plane.

$\mathrm{He}$ was full of practical ideas. To the end he was trying to develop an early warning flood system that could be broadcast on television, and a system to stop junk mail being delivered. Unfortunately, like so many of his ideas, these were either ignored or developed by other people and he never got the recognition he deserved.

He was a conscientious, charming, friendly, devoted man in the great tradition of English eccentrics as described by Evelyn Waugh. His excellent engineering skills were devoted to maintaining the swimming pool in Wendover and he swam in the early hours of the morning, without any clothes on, much to the embarrassment and surprise of the local residents.

His wife Gill, an occupational therapist, had worked with him but she predeceased him. He is survived by his son Giles. 